\title{
Access to modern energy: a review of barriers, drivers and impacts
}

\section{JACOPO BONAN}

Fondazione Eni Enrico Mattei (FEEM), Corso Magenta, 63, 20123 Milan, Italy.

Email: jacopo.bonan@feem.it

STEFANO PAREGLIO

Department of Mathematics and Physics, Università Cattolica del Sacro

Cuore; and Fondazione Eni Enrico Mattei (FEEM), Italy.

Email:Stefano.Pareglio@unicatt.it

\section{MASSIMO TAVONI}

Fondazione Eni Enrico Mattei (FEEM); and Politecnico di Milano, Italy. Email: massimo.tavoni@feem.it

Submitted 30 April 2015; revised 15 July 2016; accepted 20 April 2017; first published online 10 July 2017

\begin{abstract}
Universal access to modern energy services, in terms of access to electricity and to modern cooking facilities, has been recognized as a fundamental challenge for development. Despite strong praise for action and the deployment of large-scale electrification programs and improved cookstove (ICS) distribution campaigns, few studies have shed light on the barriers to, the enablers of and the impacts of access to energy on development outcomes, using rigorous methodologies. This paper reviews this recent strand of research, trying to fill these gaps. The authors focus on the demand-side and household perspective. Their main outcomes of interest are electricity connection and ICS adoption
\end{abstract}

The authors are grateful to Enrica Chiappero Martinetti, Nadia von Jacobi, Emanuela Colombo, Shonali Pachauri and all participants in the international workshop 'Energy Poverty and Energy Access: Global Challenges and Goals' on 10 July 2014 at FEEM for their helpful comments and suggestions. The authors thank the associate editor and three anonymous reviewers for their constructive comments, which helped to improve the manuscript. Jacopo Bonan and Stefano Pareglio acknowledge the support of the Giangiacomo Feltrinelli Foundation, Laboratorio Expo. Jacopo Bonan and Massimo Tavoni acknowledge financial support from the European Research 341 Council under the EU's Seventh Framework Programme (FP7 / 2007-2013)/ERC Grant 342 Agreement No. 336155 Project COBHAM 'The role of consumer behaviour and heterogeneity in the integrated assessment of energy and climate policies'. 
for the analysis of barriers, time allocation, labor market outcomes and welfare for the impact analysis. They provide evidence of significant wellbeing impacts of electrification and mixed evidence for cookstoves.

\section{Introduction}

Energy poverty is defined as lack, scarcity or difficulty in accessing modern energy services by households; in particular it refers to access to electricity and to modern and clean cooking facilities. The International Energy Agency estimates that currently 1.18 billion people (16 per cent of the worldwide population) lack access to electricity and 2.74 billion ( 40 per cent of the global population) rely on traditional cooking methods based on the use of biomass, with severe consequences to health due to indoor air pollution (IEA, 2016). The geographical distribution of such phenomena is uneven across the world: 84 per cent of people lacking access to modern energy services live in rural areas; people without electricity are mostly in developing Asia (51 per cent) and Africa (44 per cent); similarly, those still relying on traditional cookstoves and fuels are concentrated in developing Asia (72 per cent) and Africa (25 per cent).

In general, access to modern energy services may contribute to improvements in several domains of development, from individuals' time allocation to health, through different mechanisms that will be analyzed later. However, the strong correlation between energy access and development indicators does not necessarily imply a causal relationship. The evaluation of impacts is subject to critical methodological challenges such as selection bias, endogenous program placement, reverse causality and other confounding trends.

The main contribution of this paper is to review the available rigorous evidence emerging from the recent economic literature, by framing it into a comprehensive framework for access to modern energy services and the overall policy context. We conduct a review of the rigorous evidence on two fundamental aspects: first, we look at the barriers to and drivers of access; secondly, we analyze the impacts of access to modern energy on economic development and poverty reduction outcomes. The analysis focuses on the household level and is conducted in parallel for both the access to electricity and to modern and efficient cookstoves (improved cookstoves; ICS). The papers included in the current review meet stringent criteria in terms of identification design and investigation of causal relationships. In particular, we focus on studies proposing credible counterfactuals and/or credible sources of exogenous variation. This includes both experimental (randomized controlled trials; RCTs) and non-experimental approaches - instrumental variable (IV) estimation, longitudinal studies such as differencein-differences (DID) and fixed effects (FE), propensity score matching (PSP), regression discontinuity designs (RDD) and Heckman selection models.

The paper is organized as follows: we present the international agenda, salient determinants of successful policies to fight energy poverty, and the main challenges in the estimation of causal relationships in section 1, a conceptual framework in section 2 and the inclusion criteria rating of papers in 
this review in section 3 . In section 4 we review the barriers to and enablers of access to energy, while section 5 is on impacts. Section 6 concludes.

\subsection{Policies for fighting energy poverty}

Sustainable energy development entered the international intergovernmental agenda for the first time at the United Nations General Assembly in 1997. Since then, energy access has been recognized as a crucial aspect towards the achievement of the Millennium Development Goals, which call for the implementation of sustainable patterns of energy production and use. In 2010 the Secretary-General of the Advisory Group on Energy and Climate Change to the United Nations proposed to the international community a set of energy-related goals (AGECC, 2010), summarized by universal energy access by 2030. In 2012 the Sustainable Energy for All (SEFA) program was launched with the main goal of assuring universal access to modern and sustainable energy by 2030, improving the rate of renewables in the energy mix and promoting energy efficiency. In 2015 previous efforts and programs flowed into the new sustainable development agenda which include the goal of ensuring access to affordable, reliable, sustainable and modern energy for all (SDG7), by 2030.

Starting from the 1980s, several developing governments set policy interventions to improve and expand access to modern energy, through rural electrification and ICS diffusion programs. The main obstacles to be tackled in rural electrification programs pertain to the high investment required vis-à-vis very limited returns in the short and medium run. The cost of expanding the grid or constructing off-grid infrastructure often exceeds the returns from relatively low connection rates in remote and scattered communities with low electric consumption and low ability to pay for connection. This requires substantial subsidies. Yet, many countries have made progress in connecting remote rural areas to electricity. In particular, several emerging economies have included rural electrification programs in their agenda in order to reduce the strong urban-rural divide. Some examples of large national rural electrification programs are represented by Brazil, China and India, which have achieved an electrification rate greater than 65 per cent through significant public investments. ${ }^{1}$ Smaller countries such as Thailand, Costa Rica and Tunisia have reached even higher connection rates in the rural population (Barnes, 2007). Successful rural electrification programs have followed several models which can be considered context specific, for example through the involvement of the private sector or electric cooperatives. However, some common features seemed to have guided successful programs in their deployment (Barnes, 2007). The first is the introduction of efficient, effective and equitable subsidies. The second is the presence of an adequate and effective implementing agency, with a high degree of operating autonomy (particularly from possible political pressure) and accountability in the targets to reach. The third is adequate

${ }^{1}$ For a more detailed overview of the electrification programs in emerging countries, see Niez (2010). 
expansion plans which consider the actual needs and possibilities of communities and ensure financial viability and economic impact: premature rural electrification may miss the objective of contributing to sustainable community development if other conditions enabling economic development are not present. Fourthly, tariff policy is an important ingredient as it has to ensure financial sustainability and cost recovery on the one hand and, on the other, it has to consider customers' realistic ability to pay. Finding financial solutions for lowering the connection charges is also a driver of higher connection rates.

The policies implemented at the national level which aim to improve cooking strategies and avoid health problems related to high exposure to indoor air pollution (IAP) have followed three main strategies. The first tried to promote cleaner fuel adoption by replacing biomass with kerosene and liquefied petroleum gas (LPG). This has been the case for Ecuador and Indonesia, where poor households could benefit from subsidized kerosene for cooking (Barnes and Halpern, 2000). However, drawbacks emerged such as the high cost of kerosene and LPG together with difficulties in supplying them in remote areas, given poor infrastructure. More recently, a second practice has seemed to prevail: the development and promotion of ICS which use wood and biomass in a more efficient way while reducing exposure to air pollutants through the introduction of a chimney. The important pros of the substitution of cookstoves rely on the fact that the technology is relatively easy to upscale using local materials and producers (which may lead to job creation in the area and use of local materials); prices are affordable even for poor households and the final product is similar to traditional cookstoves, allowing a reduction of the cultural 'gap' arising from the introduction of a new technology. A third option is the introduction of small-scale bio-digesters for the production of biogas at the community and household level, although a wide diffusion of such technologies has been slow in several developing countries. ${ }^{2}$

As for rural electrification programs, several emerging countries have developed different initiatives for the diffusion of ICS for the large proportion of households still relying on traditional technologies, some of which have been deemed successful, others less so. Key features of successful programs include both supply- and demand-side aspects combined with the development of enabling institutional and market environments. From the supply side, product design aspects such as compatibility with household needs, housing, cultural and environmental conditions have been shown to be crucial factors for large-scale product take-up (Lewis and Pattanayak, 2012). Quality and durability of cookstoves are critical conditions to realize sustained improvements in efficiency and/or IAP reduction. From the demand side, efforts in filling households' information gaps about the advantages of ICS take-up through information campaigns and social marketing as well as innovative financial solutions to overcome credit constraints are key drivers of success. Enabling institutional

${ }^{2}$ For a review and classification of available cookstove and biogas technologies, see Mapelli and Mungwe (2013). 
and market conditions at the local level include the involvement of local institutions, the development of the supply chain for production and aftersale services, and the use of robust independent monitoring and evaluation tools. A useful illustration of the drivers of success and failure of large-scale national programs for ICS adoption is represented by the Chinese National Improved Stove Program (Smith et al., 1993; Sinton et al., 2004) and the National Program on Improved Chulhas in India (Kishore and Ramana, 2002; Venkataraman et al., 2010), respectively.

\subsection{The challenges of rigorous impact evaluation}

Despite the great effort and investment in the energy sector to increase rural electrification and the diffusion of modern cooking systems, relatively little is known about the effective impact of such policies on households' wellbeing. The justification of large public programs to improve the access to modern energy has often relied on supposed benefits and transformative effects on households' health, education, labor market outcomes and, ultimately, poverty level. However, there is still limited evidence to substantiate such impacts, given the methodological challenges of attribution. Assessing the impact of rural electrification or campaigns for the diffusion of ICS requires addressing the attribution issue through the use of identifications which tackle endogeneity and selection bias problems.

Different methods have been suggested to identify counterfactuals through control groups, allowing the proper comparison of outcomes and leading to correct cause-effect assessments. Impact evaluation methods using the counterfactual can be classified in two main categories: experimental and non-experimental designs. Experimental designs construct the counterfactual through the random assignment of individuals to either treatment or control groups. Non-experimental methods are used when it is not possible to directly manipulate the assignment process of project exposure, and rely on observational data derived from the observation of the natural development of events. The identification of the counterfactual using non-experimental methods requires specific, fairly strong assumptions. The most common techniques are through the use of longitudinal data using DID or FE models, PSP, RDD, IV and Heckman selection models. This review mainly focuses on works that explicitly attempt to identify the counterfactual via experimental and non-experimental methods.

\section{Conceptual framework}

Access to modern and quality energy is a fundamental input for the assessment of impacts on economic development in the sphere of households. However, it is important to consider it within a more general framework. Figure 1 shows a possible conceptual framework which includes access to energy as both output and input in a theory of change. There is a vast debate on the general conditions making modern and quality energy available to households, which spans from institutions and policies to markets, technology, and the social and natural environment. In the context of electrification, key factors are represented by policy decisions over the energy 


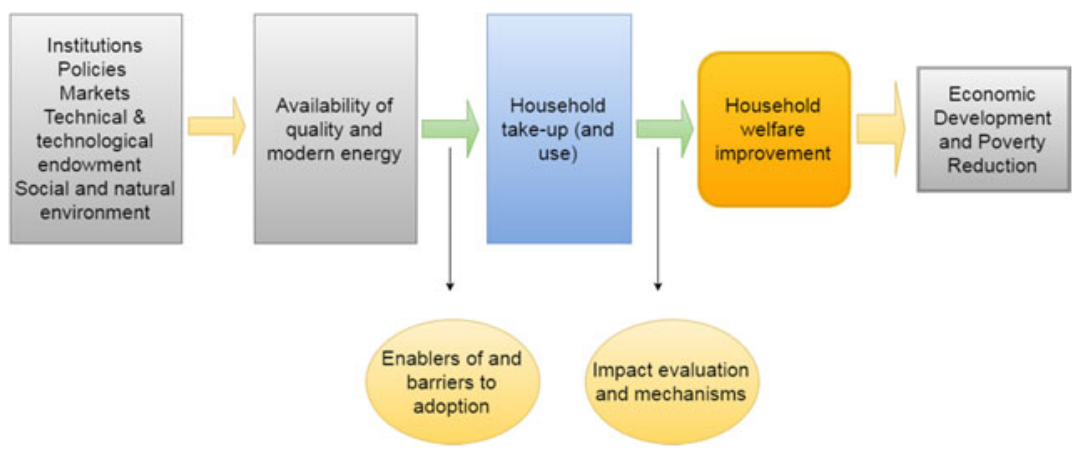

Figure 1. Conceptual framework

mix, electricity generation, transmission and distribution, public versus private supply, tariff plans, etc. In spite of their fundamental importance in the theory of change, they are not the main focus of this work. From a household perspective, accessible energy does not automatically mean actual access. Several barriers and drivers in the decision to take up the new technology need to be considered. The review of works which rigorously investigate such barriers to and drivers of adoption is one of the main objectives of this paper.

The second main focus of this review is dedicated to the investigation of impacts of access to energy on household welfare and, ultimately, on economic development and poverty reduction. We look at several mechanisms linking access to energy to the outcomes of interest and review the evidence substantiating causal links. Specific conceptual frameworks are developed for the review of causal chains for access both to electricity and to ICS. This exercise also allows us to shed light on under-researched areas.

\section{Study selection}

The selection of papers to be included in this work was done through electronic searches in bibliographic databases, backward and forward citation tracking in published and unpublished papers ('snowballing'), and selective search in institutional websites (J-PAL, 3ie, DFID). ${ }^{3}$ The criteria for including studies in this review were established along the definitions of participants, interventions, comparison groups and outcomes (PICO), following the standards of systematic reviews. A particularly strict inclusion criterion is set on the study methodology. The type of participants (and the unit of observation) includes individuals or households living in low- and middle-income countries, in accordance with the World Bank classification.

3 The search strategy cannot be defined as 'systematic' and was not conducted through the definition of an $e x$ ante protocol and comprehensive search in multiple international databases. The 'grey literature' has been purposively excluded from the current review. However, the mass of papers we end up with using this strategy is in line with systematic reviews. 
The types of interventions include, in the domain of access to electricity, the expansion of the coverage of on-grid, off-grid and decentralized power provision (micro PV and home solar systems) and improvements in the quality of the electricity supply. In the domain of cooking methods, interventions include policies and programs to promote cleaner and more efficient household energy technologies, intended in a very broad way as possible progress from traditional inefficient stoves. Eligible comparisons include both groups of people not receiving the type of intervention under study and groups receiving other types of treatment or different levels of intensity. The control group is either identified via experimental design or through the quasi-experimental methods listed below. In the domain of the analysis of barriers to and enablers of adoption, the outcome variables are electricity connection, ICS take-up and use. In the domain of impacts, outcome measures include time allocation, labor market outcomes, welfare and health. A detailed description of outcomes is provided in the following sections dedicated to the description of the reviewed evidence.

Eligible studies included, regardless of their publication status, experimental (RCTs) and quasi-experimental methods with a controlled comparison. Quasi-experimental designs required a cross-sectional and/or longitudinal comparison. For quasi-experimental designs we indicate the method of analysis used to control for endogeneity of program placement or selection bias. We include matching, panel data methods, DID, IV estimation, RDD and Heckman selection models, or combinations of them.

In order to weigh the degree of identifying assumption to obtain causal inferences as well as the credibility of results from studies with a wide range of methodologies and data sources, we use the risk of bias tool developed by the International Development Coordinating Group (IDCG) Secretariat to assess risk of bias (see Baird et al. (2013) for a similar application). This tool allows us to assess the degree of identifying assumption and the credibility of results, based on five categories: (1) selection bias and confounding; (2) spillovers, cross-overs, contamination; (3) outcome reporting; (4) analysis reporting; and (5) other risks of bias. ${ }^{4}$ In tables A2-A5 in the online appendix, available at http:/ / doi.org/10.1017/S1355770X17000201, each paper is assigned a score equal to high, medium or low. Such assessment is qualitatively taken into consideration when we discuss the evidence of causal relationships. Table A1 (online appendix) summarizes the number of articles that has been included by topic and methodology.

\section{Enablers of and barriers to household access to modern energy}

The works on barriers to and drivers of electricity connection and adoption of ICS is strongly connected to the literature on technology adoption and on the demand for environmental health improvements. This is related to heterogeneities in consumers' preferences, circumstances and constraints (see, among others, Besley and Case (1993), Pattanayak and Pfaff (2009)). The

4 The tool from Baird et al. (2013) which has been used in the paper is reported in the online appendix. 
take-up of preventive and remedial practices and products is very effective in reducing the burden of morbidity and mortality, such as malaria, HIV/AIDS and waterborne and respiratory diseases. Similarly to ICS, insecticide-treated bednets, water treatments with chlorine, condoms, menstrual cups and deworming pills are among the possible relatively easy and inexpensive solutions whose take-up is, however, quite slow. The role of subsidies and price to mitigate liquidity constraints, credit constraints, time preferences, lack of information and awareness and peer effects are among the most important barriers to health technology adoption, particularly when returns appear uncertain (see Dupas (2011) for a review).

Somehow differently from the technologies mentioned earlier, electricity connection requires the existence of a wider network of infrastructures, beyond the individual decision to connect and have important externalities in the costs of connection. This fact can have relevant consequences on the policy interventions needed to expand the coverage. However, we are convinced that the household decision to connect to electricity still presents common features with the literature mentioned.

\subsection{Electricity}

Reaching rural villages with electricity does not necessarily mean connections for all the households, as connection to the grid may be expensive. Lee et al. (2016a) make a distinction between 'off-grid' households that are too far away to connect to the grid without major investment, and 'undergrid' households that live close enough to the grid to be connected to a low-voltage line at a relatively low cost. They show that among the latter group only 5 per cent of rural households and 22 per cent of rural businesses are actually connected, even five years after the infrastructure building and despite the relatively high population density of the study area (rural Kenya). Levels of connection remain low even for relatively well-off households and businesses. In other studies and locations, households' connection in newly on-grid locations varies considerably: 23 per cent in Indonesia (Chakravorty et al., 2016), 50 per cent in India (Burlig and Preonas, 2016) and 70 per cent in Rwanda (Lenz et al., 2017).

Very few papers satisfying our inclusion criteria assess the role of barriers and drivers to the connection to the grid/mini-grid. ${ }^{5}$ The individual decision to connect seems to be linked to the price of the connection, which may range between US\$50 and US\$250; despite subsidization, such fees may be prohibitive for most poor households. In fact, while less than 5 per cent of the poorest rural households in Ghana and South Africa were connected to electricity, more than 20 per cent of those in the richest quintile were connected (Heltberg, 2003). Lee et al. (2016b) study the demand side of

5 Several papers discuss the institutional, technological, economic and contextual barriers to the deployment of rural electrification programs (both on-grid and offgrid) using mixed methods, among others, for example, Chauhan and Saini (2015) and Ahlborg and Hammar (2014). A systematic review of the effects of marketbased reforms on access to electricity in developing countries has been done by Bensch et al. (2016). 
grid connection in Kenya and find that moving away from full subsidization of connection costs leads to lower take-up rates than expected, namely 57 and 29 per cent subsidies led to a 23 and 6 per cent take-up rate, respectively. By randomly allocating 10 and 20 per cent discount vouchers for connection fees to rural Ethiopian households, Bernard and Torero (2015) find that connections increase, on average, by 18 per cent, revealing that connection fees represent a significant barrier to the adoption of electricity. Low connection rates have also been linked to low levels of understanding of payment systems or limited knowledge of the potential advantages of electricity (Ranganathan, 1993). The presence of important economic barriers to connection and electricity use is also shown in Hanna and Oliva (2015), who find that an asset transfer program in India led to a significant increase in the use of electricity as the main source of light.

Another relevant channel in household decision making towards electricity connection is others' connection behavior. Bernard and Torero (2015) find evidence of the bandwagon effect: connection to electricity carries a social status so that neighbors' connection decisions have an impact (decreasing in distance) on household connection decisions.

Other explanations for reduced demand for electricity connections include bureaucracy, low reliability of power supply and credit constraints (Lee et al., 2016b); however, they have not been directly and rigorously tested and they therefore need to be further investigated. As in many other cases of technology adoption, households may underestimate the benefits of electrification, perhaps perceiving it as a luxury good rather than a productive investment (Bernard, 2012). Related to lack of knowledge and misperceptions, Peters et al. (2009) suggest that poor households may be afraid of misunderstanding the billing system. It would be interesting to test such hypotheses against the evidence, by evaluating the cost-effectiveness of information campaigns following the electrification expansion.

Table A2 in the online appendix reports the reviewed literature on these outcomes, the geographical region where the micro-economic study has been carried out, the estimation techniques employed to identify the causal effect and the outcome of the risk of bias assessment.

The effort towards universal access should balance the necessary longterm sustainability of projects which is essential in order to attract private investments with the issue of access and affordability for the poorer. Affordability relates to the capability of households to be financially and economically capable of accessing and using electricity. The cost of the investment of individual households is related to the number of connections of geographically close households, pointing to the existence of positive externalities associated with new connections. This fact may justify mass connection campaigns at subsidized prices or stimulate the creation of innovative schemes aimed at overcoming the collective action problem, for example through group-based subsidies linked to the number of applicants (Lee et al., 2016b). Progressive tariffs, lifeline tariffs (households consuming below a certain amount per month receive a subsidy), and innovative financing solutions for connection fees, for example through microcredit or mobile payments, are among the possible tools governments 
can use to support access to and use of electricity by rural and poor households (Winkler et al., 2011). Such solutions need to be developed, designed to local context and eventually tested against evidence.

\subsection{Improved cookstoves}

The adoption of improved technologies for cooking is strictly linked to fuel choice. Several models have tried to describe energy transition dynamics in developing countries (van der Kroon et al., 2014). The idea of an energy ladder implies the movement of households towards more sophisticated energy sources and cooking tools as their income increases. This may occur through a linear process of fuel switching (Heltberg, 2004) or through energy stacking, i.e., both modern and traditional fuels and cookstoves, not being mutually exclusive, are used at the same time (Masera et al., 2000; Ruiz-Mercado et al., 2011). This review focuses on the adoption of ICS. By adoption we mean not only purchase or acquisition of all types of ICS, through any possible channel, but also sustained usage over time. Given the lack of international standards defining the degrees of 'improvement' of stoves, we include works describing the introduction of stoves providing all kinds of innovation (efficiency and/or health risks prevention) with respect to the traditional ones.

Some recent works have tried to investigate the role of the barriers that prevent adoption, daily use and maintenance of ICS, through regression analysis of the drivers of demand. The main drivers associated with ICS adoption are related to socio-economic status: income, education and urban location are positively associated, whereas socially marginalized status is negatively related to purchase and use. Price of firewood also seems to be a key factor. In some contexts, existing models of ICS do not seem to respond to local needs and preferences (Lewis and Pattanayak, 2012; Stainstreet et al., 2014). However, most such studies do not address the issue of causal inference through the identification of proper counterfactuals, and are therefore limited to the indication of correlations and relevant associations.

There are very few studies that assess the role of barriers to adoption of ICS using counterfactual designs. These studies are summarized in table A2 in the online appendix. Several of them confirm the crucial role played by prices and liquidity constraints in the decisions to buy, use and maintain ICS (Miller and Mobarak, 2013, 2014; Alem et al., 2014; Jeuland et al., 2014; Hanna et al., 2016); even despite relatively high subsidies, the percentage of uptake decisions remains relatively low (Mobarak et al., 2012).

Differences in preferences across households but also within households seem to explain differential ICS take-up rates. Miller and Mobarak (2013) find that propensity to adopt ICS differs for women and men: women have a stronger preference towards the new technology but lack sufficient authority and bargaining power within the household to impose their decision on men. Heterogeneity in user preferences for different stove features is an important predictor of take-up (Jeuland et al., 2014).

Others' decision to adopt ICS also seems to influence individual decision to adopt. For example, Miller and Mobarak (2014) highlight the role 
of opinion leaders and social networks in conveying information on the attributes of the new technology and decisions to adopt. Social influence and imitation through social networks are also found to be an important driver for ICS take-up in Bonan et al. (2017), while Beltramo et al. (2015b) find no evidence of neighbors' adoption rates on individual decision to purchase. Social marketing and communication strategies can play an important role in favoring health preventive behavior and products (Evans et al., 2014). Investigating ICS adoption through social marketing lenses is the focus of a recent strand of research ${ }^{6}$ (Lewis et al., 2015); however, very few studies using counterfactual methodologies are currently available. Levine et al. (2016) find that an offer combining a free trial period, time payments and the right to return the stove significantly increases the purchase of the product, compared to a traditional cash-andcarry offer. In a related study, Beltramo et al. (2015a) find that marketing messages conveying the benefits of ICS had no effect on willingness to pay (WTP).

Although ICS take-up is seen as a fundamental first step in climbing the energy ladder and fighting energy poverty, there are two conditions that make it possible after take-up has occurred. The first is the quality, effectiveness and suitability of ICS: the product has to be durable and it has to fit customers' needs and preferences beyond their 'improved' attributes (Rosenbaum et al., 2015). The second condition is the sustained use and maintenance of the product. ICS adoption cannot be intended as simple take-up, but has to be considered as a dynamic process involving the stacking of new and old fuels and stoves (Ruiz-Mercado et al., 2011). An example in which the two conditions are not met is given by Hanna et al. (2016), where stove breakages combined with insufficient investments in maintenance, inappropriate cleaning and use impeded sustained usage over time and eventually did not lead to the expected impacts.

Learning the drivers of adoption and diffusion and continuous use is of great relevance in order to strengthen evidence-based actions and policies. Further research should focus on the roles of household-level decision making, gender, cultural traits, liquidity and credit constraints, but also on behavioral factors to guide marketing interventions, through the involvement of local institutions and social networks (Foell et al., 2011). Testing different social marketing features would make it possible to shed more light on the role of information and preferences, whose impact on take-up is still under-researched.

Positive externalities in ICS adoption justify the introduction of subsidies or other ways to overcome households' liquidity constraints and relatively low WTP for ICS. However, such positive externalities occur only if households consistently use and maintain the products. This requires the introduction of innovative monitoring strategies which do not interfere with households' behavior (Hawthorne effect) but which can provide a systematic and objective measure of their use. The introduction of sensors

6 The Journal of Health Communication dedicated a special issue to this topic (2015, 20(1)). 
and IT-based stove use monitors can represent a scalable and cost-effective solution (Ruiz-Mercado et al., 2013; Harrell et al., 2016).

The introduction of demand-side interventions, as proposed above, is likely to be effective only in the presence of a stable and accessible supply of ICS. Strengthening the supply chain appears to be an important prerequisite for the success of any attempt to diffuse ICS in developing countries (Lewis et al., 2015). More effort in the development of strategies and policies for the improvement of the supply chain is needed, perhaps involving local institutions (Pattanayak and Pfaff, 2009). More rigorous research on the supply side and on its causal role in enhancing the diffusion of ICS is required, although the attribution of causal impacts is far more difficult in such a context.

\section{Impacts and mechanisms}

\subsection{Electricity}

Access to electricity can impact household welfare, economic development and poverty reduction through a vast range of channels and mechanisms. From a household perspective, access to electricity means the opportunity to purchase electric appliances, depending on the wattage level made available, such as lights, refrigerators, TVs, heating and cooling appliances and electric machinery for small business. The demand for electric appliances in developing countries is expected to grow dramatically in the next decades (Wolfram et al., 2012), and is shown to be non-linearly connected to income growth, assuming households' credit constraints (Gertler et al., 2016). The identification of impacts for the adoption of individual appliances appears challenging and very few studies have attempted to investigate it. Barreca et al. (2016) find that air conditioning lowered heat-related mortality in the USA and there is strong emerging evidence of the link between temperature and economic activity (Burke et al., 2015; Adhvaryu et al., 2016), which highlights the scope for adaptation strategies to climate change. Few studies assess the potential impact of refrigerators on food security and health. Gonzalez and Rossi (2007) find suggestive evidence of the impact of better quality of electricity provision, after privatization, on health outcomes related to nutrition due to the increase in refrigerator use. Media exposure can have important impacts on development outcomes (La Ferrara, 2016), particularly on female empowerment (Jensen and Oster, 2009), divorce (Chong and La Ferrara, 2009), social capital (Olken, 2009) and fertility (La Ferrara et al., 2012). Besides media exposure, the introduction of electricity also seems to negatively affect fertility, particularly in the short-run (Fetzer et al., 2013; Burlando, 2014; Grimm et al., 2015).

Electricity is also considered a fundamental driver for the development of economic opportunities and improvement in households' productivity in both agricultural and non-agricultural sectors, by providing motive power. In the agricultural sector, it can power farm machinery such as water pumps, fodder choppers, threshers, grinders and dryers. Electricity can contribute to the modernization of agriculture by extending cultivable land through irrigation. This could lead to increases in labor demand and 
productivity (Cabraal et al., 2005). In the non-agricultural sector, electricity could contribute to the development of small business opportunities, for example, in the food processing value chain, in handicraft production, carpentry and retailing. However, no empirical evidence of impacts of electricity on small business outcomes has been found. ${ }^{7}$ While several studies included in this review present some measures of agriculture or non-agriculture employment, production or revenues, none of them could disentangle the general access to electricity from the role of the access to specific electric items for productive use. This is an interesting area which deserves more research.

The first and most widespread electric appliance adopted in newly electrified contexts is lighting, particularly in remote areas (Barnes, 2007; Bensch et al., 2011; Bernard, 2012). This is motivated both by the often low wattage made available by on-grid or off-grid solutions, and by the households' relatively low ability to pay for other electric appliances. Lighting can have direct impacts on health via the substitution of more pollutant kerosene lamps, but also potentially influences the allocation of time of all household members: women and children can divert time from fuel collection to more productive activities such as studying or income generation. People can also benefit from greater flexibility in time allocation through the day and evening derived from better lighting. Electric light can also generate high saving from expenditure in alternatives, such as kerosene lamps, candles, diesel generators and batteries. By influencing the reallocation of activities and leisure, electric light can also have impacts on fertility, beyond the aforementioned effect through media exposure.

Finally, electrification may impact households' outcomes through public good benefits, such as increased security through lighted streets, better schooling and health services, lower environmental contamination and degradation (IEG, 2008). Although this is not the focus of this review, empirical evidence of such causal links remains scarce.

A representation of the causal chain linking access to electricity to economic development and poverty reduction is provided in figure A1 in the online appendix. One has to note that the attempt to evaluate the entire causal chain in one study would be too ambitious. In general, the studies which we review could only capture different subsets of the causal chain. The following sections describe the empirical evidence on the causal links between access to electricity (considered in a broader sense) and: (i) time allocation and labor market outcomes (table A3), and (ii) household expenditure, schooling and health (table A4).

\subsubsection{Time allocation and labor market}

The first set of channels through which access to energy may impact household welfare is time allocation of members and labor. This may occur through different mechanisms. Saving time from traditional

7 An ongoing randomized evaluation by Tavneet Suri and William Jack in Kenya investigates the impact of adoption of off-grid solar power on small retail businesses' revenue and profits. 
energy-connected activities (fuel collection, cooking, etc.), and extending the working day even after sunset may result in increased labor supply and employment. Connected to this, the time spent by children studying at home is also a possible relevant channel which may contribute to school attainment and performance.

Another set of mechanisms may involve improvements in productivity in the agricultural sector and/or the switch from agricultural to nonagricultural activities, to the development of which electricity contributes (small businesses and firms can invest in machinery, refrigeration, entertainment and communication appliances which demand non-agricultural labor). As a consequence of increased productivity, wages and earnings would increase, contributing to improvements in household income.

The impact of electrification on time allocation and labor market outcomes seems to be one of the most robust, although still not definitive. Several works lead to the conclusion that access to electricity impacts the way in which people allocate their time. For adults in India, for example, this can be a consequence of the shorter time allocated to collecting biofuels (Khandker et al., 2012), but it also contributes to important changes in children's lives, particularly with regard to the time dedicated to study and schooling. The impact of electricity on time spent studying at home by children seems to be supported in several papers, across different geographical contexts, technologies (both on-grid and off-grid) and identification strategies (Bensch et al., 2011; Khandker et al., 2012; Samad et al., 2013; Aguirre, 2014; Furukawa, 2014; Arraiz and Calero, 2015; Barron and Torero, 2016). Only two studies (Bernard and Torero, 2015; Grimm et al., forthcoming) find no significant effect, although in the former the authors suggest that this may be due to the relatively small time window of the study and to the fact that time allocation does not adjust in the short run, following electricity connection, while in the latter the off-grid product (pico solar PV kits) can only meet very basic energy services.

Regarding adults' time allocation and labor activities, the evidence suggests mild increases in employment and labor supply, particularly for women, non-agricultural activities and more formal activities. ${ }^{8}$ However, the size of such effects varies significantly across studies and geographical areas. The evidence of impact of electricity on wages, earnings and income also seems to point to the direction of improvements, although less consistently than the case of employment. For example, Dinkelman (2011) finds higher earnings for men (not for women) but no average effects on wages. Higher wages for women are found by Dasso and Fernandez (2015). Similarly, Khandker et al. (2013) show significant increases in household incomes, via improvements in non-agricultural activities, but no effect on wages. Increases in non-agricultural income are also supported in studies by Dinkelman (2011), Lipscomb et al. (2013) and Chakravorty et al. (2016). Reductions in electricity outages and increases in hours of electricity

${ }^{8}$ One has to note that, once again, Bernard and Torero (2015) find no effect on time spent on income-generating activities, with the caveat of the short-term perspective. 
provision per day generate relevant improvements in non-agricultural incomes in rural India (Chakravorty et al., 2014). Other studies find no evidence of improvements in income (Bensch et al., 2011; Arraiz and Calero, 2015).

Taken together, the results, summarized in table A2 of the online appendix, seem to support the mechanism of substitution from agricultural to non-agricultural activities, leading to gains in productivity and wages, and ultimately leading to income increases and welfare improvements.

\subsubsection{Expenditure}

Changes in the allocation of time towards more productive activities, as well as higher earnings and possibly income should be reflected in variation in consumption and expenditure which may ultimately lead to household welfare improvement. Most studies evaluating the effect of ongrid connection find significant increases in total expenditure accompanied by rises in energy expenditure (Bensch et al., 2011; van de Walle et al., 2015; Chakravorty et al., 2016), while access to off-grid such as solar PV seems to lead to lower expenditure in energy sources (Samad et al., 2013; Arraiz and Calero, 2015; Grimm et al., forthcoming). However, one has to note that the number of studies looking at this aspect is still too limited to draw definitive conclusions.

\subsubsection{Schooling}

The impact of electricity on schooling outcomes is somehow mixed. It has positive effects on the enrolment and years of schooling of Indian girls (van de Walle et al., 2015). In other studies such results are confirmed for both boys and girls in India, Vietnam, Brazil and Peru (Khandker et al., 2012, 2013; Lipscomb et al., 2013; Arraiz and Calero, 2015). However, no effects on enrolment, and negative effects on attendance and school performance are found in other studies in India, Honduras and Uganda (Squires, 2015; Burlig and Preonas, 2016). The impact of providing solar lamps to students is still inconclusive (Furukawa, 2014; Hassan and Lucchino, 2016; Kudo et al., 2016). These findings open up the risk of occurrence of a perverse effect of electricity on children's educational outcomes. This may arise, for example, through the substitution for their parents in housing chores or their direct employment in the productive sector, given the higher opportunity cost of education. This topic definitely deserves further investigation.

\subsubsection{Health}

The evidence of the impact of electricity on health outcomes is extremely limited and mainly explores the role of two channels. The first is the effect of the introduction of refrigerators on children's health through better nutrition and less food poisoning (Gonzalez and Rossi, 2007). The second is through the substitution of kerosene lamps with electric bulbs through decreases in IAP exposure and respiratory diseases (Samad et al., 2013; Barron and Torero, 2016). While inconclusive evidence is found on the first 
channel, the second channel seems to be supported. An impact evaluation analysis of electrification on a wider set of outcome indicators and for a larger time span is provided by Lipscomb et al. (2013) for Brazil. The authors show the positive impact of electrification on development indicators such as the Human Development Index (HDI), mainly led by the income and schooling components of the index.

\subsubsection{Discussion}

The impact of electrification is not limited to rural households that are connected to the grid. Access to electricity also has externality effects on other non-connected villages. The benefits of rural electrification are shown to spill over to households not connected to the grid (van de Walle et al., 2013; Lenz et al., 2017). The externality effect of electricity operating through the community is also confirmed in Burlando (2014), where villages affected by a long power outage, regardless of their level of electrification, experienced significant increases in births.

In light of the analysis conducted and summarized in table A3 (online appendix), electrification seems to be beneficial for households' welfare, along the causal chain presented in the conceptual framework. However, one has to note that the dimension of benefits seems to vary across geographical regions. In particular, the impacts in the African context, after excluding the case of South Africa in Dinkelman's (2011) study, seem to be quite modest (Peters and Sievert, 2016). The low access to markets, small role of the private sector and lack of other important infrastructure may have played a role in preventing or slowing down the impacts of access to electricity on productivity and labor opportunities in the non-agricultural sector. In such a context, improving the productivity of the agricultural sector, for example through the development of improved irrigation systems, may lead to improvement in income, even in the short to mid-term. However, on this aspect research is silent. Although more evidence on the other channels is available, it is often difficult to summarize the results and conduct meta-analysis, given the many differences in type of energy provision (for electrification, the range is from high-wattage grid, to home solar systems), the differences in the measures of outcomes, and the reliability of studies, which pose big challenges in drawing common lessons. Moreover, most studies reviewed do not control or correct for multiple hypothesis testing, which may lead to over-rejection of null hypothesis and overestimation of program impacts (List et al., 2016). ${ }^{9}$

\subsection{Improved cookstoves}

The use of ICS may have positive consequences on household welfare and sustainable development from several points of view: health, time allocation and reduced expenditure in fuels, due to efficiency gains. A graphical representation of the conceptual framework going from access to ICS to

${ }^{9}$ However, correction for multiple hypothesis testing has not been considered as a parameter in the assessment of the risk of bias. 
household welfare, through different channels, is provided in figure A2 in the online appendix.

Regarding the first channel, the World Health Organization (WHO) claims that IAP caused by the use of traditional cooking stoves and fuels such as firewood and biomass has severe consequences on health. Indoor smoke inhalation is among the underlying causes of pneumonia and heart diseases, which are among the leading causes of the global burden of disease (Ezzati and Kammen, 2001). Household air pollution is estimated to be responsible for about 4 million deaths per year (Martin et al., 2011; Lim et al., 2013). Such numbers are greater than deaths from malaria, HIV / AIDS and tuberculosis (WHO, 2008), which are expected to decrease substantially by 2030, whereas the current pace of fatal respiratory diseases due to IAP is not expected to decrease. The adverse effects of IAP on health are particularly severe in women and children (Smith et al., 2004). The adoption of ICS can therefore contribute to a decrease in morbidity, particularly that related to respiratory diseases, through the lower exposure to IAP.

Inefficient stoves require longer cooking and fuel-gathering times. This task is mainly carried out by women and children, who divert time from education and income-generating activities (Barnes and Toman, 2006), ${ }^{10}$ although these aspects are strongly related to cultural and behavioral traits which differ from place to place and may slacken the pace of change. The adoption of ICS could therefore contribute to a reallocation of time towards more productive activities, such as study and income generation.

Finally, more efficient stoves can generate a decrease in fuel consumption and expenditure, with the possibility of diverting consequent savings into other expenditures, perhaps more productive.

Table A4 in the online appendix presents the main contribution of the literature on the impacts of ICS adoption.

\subsubsection{Health}

Several studies seem to imply that changes in cooking technologies reduce the incidence of acute respiratory infections. In general, a large strand of the literature in epidemiology and environmental science supports the existence of a strong positive association between IAP and negative health outcomes (Dutta et al., 2007; Zhang and Smith, 2007), as well as between cooking fuels and morbidity (among them are Ezzati and Kammen, 2002; Gajate-Garrido, 2013; Mueller et al., 2013; Silwal and McKay, 2015). However most evidence relies on observational studies and is unable to identify causal effects: the choice of cooking fuel and stoves may be related to unobserved health behavior which also affects health outcomes. For example, better respiratory health in households that cook with cleaner fuels may

${ }^{10}$ Charmes (2006) analyses time use in several Sub-Saharan African countries, by looking at large-scale surveys, and finds that women spend three to five times as much time as men in domestic activities like collecting firewood and cooking. However, if we look at the two activities separately, it turns out that the picture is more balanced between men and women for firewood collection, whereas cooking activities are largely dominated by women. 
be due to better access to information on health prevention which may also impact on other health-related behaviors (Duflo et al., 2008). Moreover, many studies do not consider the possible mitigation of smoke inhalation reduction due to the behavioral responses of people who may not necessarily properly use and maintain cookstoves over time, after the first wave of promotion and distribution. This commonly leads to situations where reductions in IAP in the field are significantly lower than those measured during laboratory tests.

Only a handful of studies evaluate the impacts on health of ICS using randomized controlled field trials. The project RESPIRE (Randomized Exposure Study of Pollution Indoors and Respiratory Effects) is a medical investigation on the respiratory consequences of IAP and on the potential benefits from the introduction of more modern techniques in Guatemala. The use of ICS reduces carbon monoxide exposure by 50-60 per cent, and significantly reduces the risk of developing respiratory diseases such as pneumonia, over the 18 months following the distribution of cookstoves (Smith-Sivertsen et al., 2009; Smith et al., 2011). ${ }^{11}$ Another study in India, based on a longer time span and on a larger sample, shows that the introduction of modern cooking stoves has only modest health effects which tend to vanish in the longer period (Hanna et al., 2016). This is mainly due to the fact that the use of such new technologies is not always continued in time, and maintenance is often neglected. Similarly, Beltramo and Levine (2013) find no effect on health (exposure to carbon monoxide or self-reported respiratory symptoms) from the take-up of a solar oven in Senegal. This was due to the inappropriateness of the product design to the local needs. Significant reductions in health problems, respiratory diseases and eye problems are found in other studies (Yu, 2011; Burwen and Levine, 2012; Bensch and Peters, 2015); however, they are based on self-reporting.

\subsubsection{Time allocation, fuel use and expenditures}

Rigorous evidence on the role of ICS on time allocation, female and children's conditions is quite scarce (Kohlin et al., 2011). The success of ICS adoption on time allocation, fuel use and expenditure in the few rigorous studies analyzed largely varies across studies. In some works, significant reductions in time spent in fuel collection, fuel consumption and cooking time are observed (Adrianzén Agurto, 2013; Bensch and Peters, 2013, 2015; Bensch et al., 2015; Brooks et al., 2016), while in others no such effects are found (Burwen and Levine, 2012; Beltramo and Levine, 2013; Hanna et al., 2016).

\subsubsection{Discussion}

As previously discussed, the benefits of ICS on household welfare are strictly related to two main issues: first the quality, suitability to the context

${ }^{11}$ It has to be noted, though, that no significant reduction in respiratory problems was found through physician assessments, while significant effects emerged from field worker assessments. 
and durability of ICS; and secondly the behavioral component which leads to adoption, intended as take-up and sustained use over time. On the first aspect, new ICS diffusion campaigns should first assess the suitability of product design to local needs, cultural and environmental conditions. For example, one should consider that in some contexts multiple stoves are used simultaneously, the new and the traditional ones (Ruiz-Mercado et al., 2011), and that stoves need to be large enough to accommodate extended families which cook on a centralized basis to generate economies of scale (Beltramo and Levine, 2013; Bonan et al., 2017). On the second aspect, new policies should acknowledge the existence of a gap from ICS takeup to actual, continuous and sustained usage over time. In order to cover 'the last mile', efforts should not just focus on the distribution side, but should incorporate adequate interventions to induce households' behavioral change. This is a crucial condition towards ultimately realizing the expected benefits in household welfare and the positive externalities. These may include, for example, informational campaigns, the provision of some sort of after-sale service mechanism to support ICS maintenance, nudges and incentives. Multiplier effects may be obtained by exploiting natural social network dynamics and thorough marketing strategies.

On the research front, more evidence is needed to test products and cost-effectiveness of models in different contexts. Researchers need to complement self-reporting with objective measures of usage and impacts. Such an exercise is particularly costly, but it is extremely useful if one wants to minimize measurement error and self-reporting bias. Useful examples for objective IAP measures, ICS usage monitoring and morbidity assessments are provided in Barron and Torero (2016), Ruiz-Mercado et al. (2011), Beltramo and Levine (2013) and Hanna et al. (2016). This may induce the development of innovative financing mechanisms, for example through carbon and impact finance.

\section{Conclusions}

Large global imbalances and inequity in access to energy have recently stimulated an important policy debate which has influenced the post-2015 development agenda, leading to the incorporation of universal access to affordable, reliable and modern energy in the Sustainable Development Goals. Access to electricity, particularly in rural areas, and the introduction of ICS technologies beyond the use of wood and biomass, are crucial development challenges because of their close link to and implication for household health, education, welfare and the labor market. Although a great effort over the last decades has been made to monitor progress and report initiatives, rigorous impact evaluation studies of programs (at all scales) are rare. This paper reviews the most recent literature on the barriers to, enablers of and impact evaluation of access to electrification and adoption of ICS on several relevant outcomes, based on solid identification strategies and estimation techniques.

This review unveiled some important elements beyond the common consideration of grid expansion as a panacea for development. New emerging 
challenges are related to the relatively low connection rates in on-grid areas and the relatively little impact of electricity expansion both in the short and the mid-run particularly in some areas such as the African context, where effects are somehow smaller or take longer to emerge. More evidence involving rigorous technique is needed to better understand the barriers to electricity connection and when, where and after how long electricity access has the greatest impact.

Electrification policies should consider two aspects more thoroughly: first, the role of barriers to connections, finding innovative solutions incorporating household decision making. Such solutions should be tested against the evidence. Secondly, policy makers should balance the actual quantified benefits and the different costs of electricity provision, depending on the different distribution options. This should take into consideration the documented good success of off-grid solutions for the provision of basic energy services.

Similar considerations hold for ICS diffusion policies. Enhancing household adoption requires more effort to understand and develop both the supply and the demand side. The large varieties of products currently available in the decentralized markets, and the lack of standard of quality and testing metrics, pose important challenges. Although 'fit for all' products cannot be viable solutions, ICS need to fit local contexts and preferences. Given the important private and public benefits they can generate, innovative interventions should focus on financing mechanisms, coupled with demand-side considerations on household economic and behavioral constraints in climbing the energy ladder. This may imply the introduction of marketing interventions and post-sale services in order to maximize take-up and sustained usage over time.

Understanding the impact of access to modern energy services on households', firms' and communities' outcomes is the best way to help decision makers implement effective policies and interventions. Evidence-based considerations on the efficacy and efficiency of modern energy adoption enhancing strategies are extremely important when budget constraints for development are limited and markets are not yet mature.

\section{Supplementary material and methods}

To view supplementary material for this article, please visit https://doi. org/10.1017/S1355770X17000201.

\section{References}

Adhvaryu, A., N. Kala, and A. Nyshadham (2016), 'The light and the heat: productivity co-benefits of energy-saving technology', [Available at] http:/ /economics.yale.edu/sites/default/files/adhvaryu.pdf.

Adrianzén Agurto, M. (2013), 'Improved cooking stoves and firewood consumption: quasi-experimental evidence from the Northern Peruvian Andes', Ecological Economics 89: 135-143.

AGECC (2010), Energy for a Sustainable Future, New York: Advisory Group on Energy and Climate Change. 
Aguirre, J. (2014), 'Impact of rural electrification on education: a case study from Peru', [Available at] http://udep.edu.pe/cceeee/files/2014/07/1B_3_Aguirre. pdf.

Ahlborg, H. and L. Hammar (2014), 'Drivers and barriers to rural electrification in Tanzania and Mozambique - grid-extension, off-grid, and renewable energy technologies', Renewable Energy 61: 117-124.

Alcázar, L., E. Nakasone, and M. Torero (2007), 'Provision of public services and welfare of the poor: learning from an incomplete electricity privatization process in rural Peru', Working Paper No. 3232, Inter-American Development Bank, Washington, DC.

Alem, Y., S. Hassen, and G. Kohlin (2014), 'Adoption and disadoption of electric cookstoves in urban Ethiopia: evidence from panel data', Resource and Energy Economics 38: 110-124.

Arraiz, I. and C. Calero (2015), 'From candles to light: the impact of rural electrification', Working Paper No IDB-WP-599, Inter-American Development Bank, Washington, DC.

Baird, S., F.H.G. Ferreira, B. Özler, and M. Woolcock (2013), 'Relative effectiveness of conditional and unconditional cash transfers for schooling outcomes in developing countries: a systematic review', Campbell Systematic Reviews 9.

Barnes, D.F. (2007), The Challenge of Rural Electrification: Strategies for Developing Countries, Washington, DC: Resources for the Future.

Barnes, D. and J. Halpern (2000), 'The role of energy subsidies', in P.J. Brook and S. Smith (eds), Energy and Development Report 2000: Energy Services for the World's Poor, Washington, DC: World Bank.

Barnes, D. and M. Toman (2006), 'Energy, equity and economic development', in R. Lopez and M. Toman (eds), Economic Development and Environmental Sustainability: New Policy Options, Oxford: Oxford University Press.

Barreca, A., K. Clay, O. Deschenes, M. Greenstone, and M. Shapiro (2016), 'Adapting to climate change: the remarkable decline in the US temperature-mortality relationship over the twentieth century', Journal of Political Economy 124(1): 105-159.

Barron M. and M. Torero (2016), 'Household electrification and indoor air pollution', [Available at] https://www.ocf.berkeley.edu/ manuelb/Research/IAP/IAPJan2016.pdf.

Beltramo, T. and D.I. Levine (2013), 'The effect of solar ovens on fuel use, emissions and health: results from a randomised controlled trial', Journal of Development Effectiveness 5: 178-207.

Beltramo, T., G. Blalock, D.I. Levine, and A.M. Simons (2015a), 'The effect of marketing messages and payment over time on willingness to pay for fuel-efficient cookstoves', Journal of Economic Behavior E Organization 118: 333-345.

Beltramo, T., G. Blalock, D.I. Levine, and A.M. Simons (2015b), 'Does peer use influence adoption of efficient cookstoves? Evidence from a randomized controlled trial in Uganda', Journal of Health Communication 20(suppl. 1): 55-66.

Bensch, G. and J. Peters (2013), 'Alleviating deforestation pressure? Impacts of improved stove dissemination on charcoal consumption in urban Senegal', Land Economics 89(4): 676-698.

Bensch, G. and J. Peters (2015), 'The intensive margin of technology adoption experimental evidence on improved cooking stoves in rural Senegal', Journal of Health Economics 42: 44-63.

Bensch, G., J. Kluve, and J. Peters (2011), 'Impacts of rural electrification in Rwanda', Journal of Development Effectiveness 3: 567-588.

Bensch, G., M. Grimm, and J. Peters (2015), 'Why do households forego high returns from technology adoption? Evidence from improved cooking stoves in Burkina Faso', Journal of Economic Behavior \& Organization 116: 187-205. 
Bensch, G., M. Sievert, J. Langbein, and N. Kneppel (2016), 'Effects and mechanisms of market-based reforms on access to electricity in developing countries: a systematic review', 3ie Systematic Review 31, London: International Initiative for Impact Evaluation (3ie).

Bernard, T. (2012), 'Impact analysis of rural electrification projects in Sub-Saharan Africa', World Bank Research Observer 27(1): 33-51.

Bernard, T. and M. Torero (2015), 'Social interaction effects and connection to electricity: experimental evidence from rural Ethiopia', Economic Development and Cultural Change 63(3): 459-484.

Besley, T. and A. Case (1993), 'Modeling technology adoption in developing countries', American Economic Review 83: 396-402.

Bonan J., P. Battiston, J. Bleck, P. LeMay-Boucher, S. Pareglio, B. Sarr, and M. Tavoni (2017), 'Social interaction and technology adoption: experimental evidence from improved cookstoves in Mali', Unpublished manuscript.

Brooks, N., V. Bhojvaid, M.A. Jeuland, J.J. Lewis, O. Patange, and S.K. Pattanayak (2016), 'How much do alternative cookstoves reduce biomass fuel use? Evidence from North India', Resource and Energy Economics 43: 153-171.

Burke, M., S.M Hsiang, and E. Miguel (2015), 'Global non-linear effect of temperature on economic production', Nature 527: 235-239.

Burlando, A. (2014), 'Power outages, power externalities, and baby booms', Demography 51: 1477-1500.

Burlig, F. and L. Preonas (2016), 'Out of the darkness and into the light? Development effects of electrification in India', Energy Institute at Haas Working Paper No. 268, Berkeley, CA.

Burwen, J. and D.I. Levine (2012), 'A rapid assessment randomized-controlled trial of improved cookstoves in rural Ghana', Energy for Sustainable Development 16: 328-338.

Cabraal, R.A., D.F. Barnes, and S.G. Agarwal (2005), 'Productive uses of energy for rural development', Annual Review of Environment and Resources 30: 117-144.

Chakravorty, U., M. Pelli, and B. Ural Marchand (2014), 'Does the quality of electricity matter? Evidence from rural India', Journal of Economic Behavior and Organization 107: 228-247.

Chakravorty, U., K. Emerick, and M.-L. Ravago (2016), 'Lighting up the last mile: the benefits and costs of extending electricity to the rural poor', RFF Discussion Paper No. 16-22, Resources for the Future, Washington, DC.

Charmes, J. (2006), 'A review of empirical evidence on time use in Africa from UNsponsored surveys', in C.M. Blackden and Q. Wodon (eds), Time Use and Poverty in Sub-Saharan Africa, Washington, DC: World Bank.

Chauhan, A. and R.P. Saini (2015), 'Renewable energy based off-grid rural electrification in Uttarakhand state of India: technology options, modelling method, barriers and recommendations', Renewable and Sustainable Energy Reviews 51: 662-681.

Chong, A. and E. La Ferrara (2009), 'Television and divorce: evidence from Brazilian novelas', Journal of the European Economic Association 7: 458-468.

Dasso, R. and F. Fernandez (2015), 'The effects of electrification on employment in rural Peru', IZA Journal of Labor \& Development 4: 6; doi:10.1186/s40175-0150028-4.

Dinkelman, T. (2011), 'The effects of rural electrification on employment: new evidence from South Africa', American Economic Review 101(7): 3078-3108.

Duflo, E., M. Greenstone, and R. Hanna (2008), 'Indoor air pollution, health and economic well-being', S.A.P.I.EN.S. 1(1).

Dupas, P. (2011), 'Health behavior in developing countries',Annual Review of Economics 3: 425-449. 
Dutta, K., K.N. Shields, R. Edwards, and K.R. Smith (2007), 'Impact of improved biomass cookstoves on indoor air quality near Pune, India', Energy for Sustainable Development 11: 19-32.

Evans, W.D., S.K. Pattanayak, S. Young, J. Buszin, S. Rai, and J.W. Bihm (2014), 'Social marketing of water and sanitation products: a systematic review of peer-reviewed literature', Social Science \& Medicine 110: 18-25.

Ezzati, M. and D.M. Kammen (2001), 'Indoor air pollution from biomass combustion and acute respiratory infections in Kenya: an exposure-response study', The Lancet 358: 619-624.

Ezzati, M. and D.M. Kammen (2002), 'Evaluating the health benefits of transitions in household energy technologies in Kenya',Energy Policy 30: 815-826.

Fetzer T., O. Pardo, and A. Shanghavi (2013), 'An urban legend?! Power rationing, fertility and its effects on mothers', CEP Discussion Paper No. 1247, Centre for Economic Performance, London.

Foell, W., S. Pachauri, D. Spreng, and H. Zerriffi (2011), 'Household cooking fuels and technologies in developing economies', Energy Policy 39(12): 7487-7498.

Furukawa, C. (2014), 'Do solar lamps help children study? Contrary evidence from a pilot study in Uganda', Journal of Development Studies 50(2): 319-341.

Gajate-Garrido, G. (2013), 'The impact of indoor air pollution on the incidence of life threatening respiratory illnesses: evidence from young children in Peru', Journal of Development Studies 49(4): 500-515.

Gertler, P.J., O. Shelef, C.D. Wolfram, and A. Fuchs (2016), 'The demand for energyusing assets among the world's rising middle classes', American Economic Review 106: $1366-1401$.

Gonzalez, M. and M.A. Rossi (2007), 'The impact of electricity sector privatization on public health', IADB Working Paper No. R-524, Inter-American Development Bank, Washington, DC.

Grimm, M., R. Sparrow, and L. Tasciotti (2015), 'Does electrification spur the fertility transition? Evidence from Indonesia', Demography 52: 1773-1796.

Grimm, M., A. Munyehirwe, J. Peters, and M. Sievert (forthcoming), 'A first step up the energy ladder? Low cost solar kits and household's welfare in rural Rwanda', World Bank Economic Review.

Grogan, L. and A. Sadanand (2013), 'Rural electrification and employment in poor countries: evidence from Nicaragua', World Development 43: 252-265.

Hanna, R. and P. Oliva (2015), 'Moving up the energy ladder: the effect of an increase in economic well-being on the fuel consumption choices of the poor in India', American Economic Review 105: 242-246.

Hanna, R., E. Duflo, and M. Greenstone (2016), 'Up in smoke: the influence of household behavior on the long-run impact of improved cooking stoves', American Economic Journal: Economic Policy 8(1): 80-114.

Harrell, S., T. Beltramo, G. Blalock, J. Kyayesimira, D.I. Levine, and A.M. Simons (2016), 'What is a "meal"? Comparative methods of auditing carbon offset compliance for fuel-efficient cookstoves', Ecological Economics 128: $8-16$.

Hassan, F. and P. Lucchino (2016), 'Powering education', CEP Discussion Paper No. 1438, Centre for Economic Performance, London.

Heltberg, R. (2003), 'Household fuel and energy use in developing countries: a multi-country study', ESMAP Technical Paper No. 42, World Bank, Washington, DC.

Heltberg, R. (2004), 'Fuel switching: evidence from eight developing countries', Energy Economics 26: 869-887.

IEA (International Energy Agency) (2016), World Energy Outlook, Paris: Organization for Economic Cooperation and Development. 
IEG (2008), The Welfare Impacts of Rural Electrification: A Reassessment of the Costs and Benefits, IEG Impact Evaluation, Washington, DC: World Bank.

Jensen, R. and E. Oster (2009), 'The power of TV: cable television and women's status in India', Quarterly Journal of Economics 124: 1057-1094.

Jeuland, M., S.K. Pattanayak, T. Soo, and J. Sheng (2014), 'Preference heterogeneity and adoption of environmental health improvements: evidence from a cookstove promotion experiment', Duke Environmental and Energy Economics Working Paper No. EE14-10, Duke Nicholas Institute, Durham, NC.

Khandker, S.R., D.F Barnes, H.A. Samad, and A. Rubaba (2012), 'Who benefits most from rural electrification? Evidence in India', Policy Research Working Paper No. 6095, World Bank, Washington, DC.

Khandker, S.R., D.F Barnes, and H.A. Samad (2013), ‘Welfare impacts of rural electrification: a panel data analysis from Vietnam', Economic Development and Cultural Change 61: 659-692.

Kishore, V.V.N. and P.V. Ramana (2002), 'Improved cookstoves in rural India: how improved are they? A critique of the perceived benefits from the National Programme on Improved Chulhas (NPIC)', Energy 27: 47-63.

Kohlin, G., E.O. Sills, S.K. Pattanayak, and C. Wilfong (2011), 'Energy, gender and development: what are the linkages? Where is the evidence?', Policy Research Working Paper No. 125, World Bank, Washington, DC.

Kudo, Y., S.A. Shonchoy, and K. Takahashi (2016), 'Can solar lanterns improve youth academic performance? Experimental evidence from Bangladesh', Unpublished manuscript.

La Ferrara, E. (2016), 'Mass media and social change: can we use television to fight poverty?', Journal of the European Economic Association 14(4): 791-827.

La Ferrara, E., A. Chong, and S. Duryea (2012), 'Soap operas and fertility: evidence from Brazil', American Economic Journal: Applied Economics 4: 1-31.

Lee, K., E. Brewer, C. Christiano, F. Meyo, E. Miguel, M. Podolsky, J. Rosa, and C. Wolfram (2016a), 'Electrification for "under grid" households in rural Kenya', Development Engineering 1: 26-35.

Lee, K., E. Miguel, and C. Wolfram (2016b), 'Experimental evidence on the demand for and costs of rural electrification', NBER Working Paper No. 22292, National Bureau of Economic Research, Washington, DC.

Lenz, L., A. Munyehirwe, J. Peters, and M. Sievert (2017), 'Does large-scale infrastructure investment alleviate poverty? Impacts of Rwanda's electricity access roll-out program', World Development 89: 88-110.

Levine, D.I., T. Beltramo, G. Blalock, and C. Cotterman (2016), 'What impedes efficient adoption of products? Evidence from randomized sales offers for fuelefficient cookstoves in Uganda', CEGA Working Paper No. 59, Center for Effective Global Action, Berkeley, CA.

Lewis, J.J. and S.K. Pattanayak (2012), 'Who adopts improved fuels and cookstoves? A systematic review', Environmental Health Perspectives 120(5): 637-645.

Lewis, J.J., V. Bhojvaid, N. Brooks, I. Das, M.A. Jeuland, O. Patange, and S.K. Pattanayak (2015), 'Piloting improved cookstoves in India', Journal of Health Communication 20: 28-42.

Lim S.S., T. Vos, A.D. Flaxman, et al. (2013), 'A comparative risk assessment of burden of disease and injury attributable to 67 risk factors and risk factor clusters in 21 regions, 1990-2010: a systematic analysis for the Global Burden of Disease Study 2010', The Lancet 380: 2224-2260.

Lipscomb, M., A.M. Mobarak, and T. Barham (2013), 'Development effects of electrification: evidence from the topographic placement of hydropower plants in Brazil', American Economic Journal: Applied Economics 5: 200-231. 
List, J.A., A.M. Shaikh, and Y. Xu (2016), 'Multiple hypothesis testing in experimental economics', NBER Working Paper No. 21875, National Bureau of Economic Research, Washington, DC.

Mapelli, F. and J.N. Mungwe (2013), 'Modern energies services for cooking: from improved cook-stoves to domestic and community biogas based systems', in E. Colombo, S. Bologna and D. Masera (eds), Renewable Energy for Unleashing Sustainable Development, Cham: Springer International, pp. 43-74.

Martin, W.J., R.I. Glass, J.M. Balbus, and F.S. Collins (2011), 'A major environmental cause of death', Science 334: 180-181.

Masera, O.R., B.D. Saatkamp, and D.M. Kammen (2000), 'From linear fuel switching to multiple cooking strategies: a critique and alternative to the energy ladder model', World Development 28: 2083-2103.

Miller, G. and A.M. Mobarak (2013), 'Gender differences in preferences, intrahousehold externalities, and low demand for improved cookstoves', NBER Working Paper No. 18964, National Bureau of Economic Research, Washington, DC.

Miller, G. and A.M. Mobarak (2014), 'Learning about technologies through opinion leaders and social network: experimental evidence on non-traditional stoves in rural Bangladesh', Marketing Science 34(4): 480-499.

Mobarak, A.M., P. Dwivedi, R. Bailis, L. Hildemann, and G. Miller (2012), 'Low demand for nontraditional cookstove technologies', Proceedings of the National Academy of Sciences 109: 10815-10820.

Mueller, V., A. Pfaff, J. Peabody, Y. Liu, and K.R. Smith (2013), 'Improving stove evaluation using survey data: who received which intervention matters', Ecological Economics 93: 301-312.

Niez, A. (2010), 'Comparative study on rural electrification policies in emerging economies: key successful policies', Information Paper No. 2010/3. International Energy Agency, Paris.

Olken, B.A. (2009), 'Do television and radio destroy social capital? Evidence from Indonesian villages', American Economic Journal: Applied Economics 1: 1-33.

Pattanayak, S.K. and A. Pfaff (2009), 'Behavior, environment, and health in developing countries: evaluation and valuation', Annual Review of Resource Economics 1: 183-217.

Peters, J. and M. Sievert (2016), 'Impacts of rural electrification revisited - the African context', Journal of Development Effectiveness 8(3): 327-345.

Peters, J., M. Harsdorff, and F. Ziegler (2009), 'Rural electrification: accelerating impacts with complementary services', Energy for Sustainable Development 13: $38-42$.

Ranganathan, V. (1993), 'Rural electrification revisited', Energy Policy 21(2): 142-151.

Rosenbaum, J., E. Derby, and K. Dutta (2015), 'Understanding consumer preference and willingness to pay for improved cookstoves in Bangladesh', Journal of Health Communication 20(suppl. 1): 20-27.

Ruiz-Mercado, I., O. Masera, H. Zamora, and K.R. Smith (2011), 'Adoption and sustained use of improved cookstoves', Energy Policy 39(12): 7557-7566.

Ruiz-Mercado, I., E. Canuz, J.L. Walker, and K.R. Smith (2013), 'Quantitative metrics of stove adoption using stove use monitors (SUMs)', Biomass and Bioenergy 57: 136-148.

Samad, H.A., S.R. Khandker, M. Asaduzzaman, and M. Yunus (2013), 'The benefits of solar home systems: an analysis from Bangladesh', Policy Research Working Paper No. 6724, World Bank, Washington, DC.

Silwal, A.R. and A. McKay (2015), 'The impact of cooking with firewood on respiratory health: evidence from Indonesia', Journal of Development Studies 51(12): 1619-1633. 
Sinton, J.E., K.R. Smith, J.W. Peabody, L. Yaping, Z. Xiliang, R. Edwards, and G. Quan (2004), 'An assessment of programs to promote improved household stoves in China', Energy for Sustainable Development 8: 33-52.

Smith, K.R., G. Shuhua, H. Kun, and Q. Daxiong (1993), 'One hundred million improved cookstoves in China: how was it done?', World Development 21: 941-961.

Smith, K.R., S. Mehta, and M.A. Desai (2004), 'Indoor smoke from solid fuels: assessing the environmental burden of disease at national and local levels', Environmental Burden of Disease Series No. 4, World Health Organization, Geneva.

Smith, K.R., J.P. McCracken, M.W. Weber, et al. (2011), 'Effect of reduction in household air pollution on childhood pneumonia in Guatemala (RESPIRE): a randomised controlled trial', The Lancet 378: 1717-1726.

Smith-Sivertsen T., E. Díaz, D. Pope, et al. (2009), 'Effect of reducing indoor air pollution on women's respiratory symptoms and lung function: RESPIRE Guatemala randomized trial', American Journal of Epidemiology 170(2): 211-220.

Squires, T. (2015), 'The impact of access to electricity on education: evidence from Honduras', [Available at] https://economics.ucr.edu/seminars_colloquia/201415/applied_economics/Squires_JMP_Electricity.pdf.

Stainstreet, D., E. Puzzolo, N. Bruce, D. Pope, and E. Rehfuess (2014), 'Factors influencing household uptake of improved solid fuel stoves in low- and middle-income countries: a qualitative systematic review', International Journal of Environmental Research and Public Health 11(8): 8228-8250.

van der Kroon, B., R. Brouwer, and P. van Beukering (2014), 'The impact of the household decision environment on fuel choice behavior', Energy Economics 44: 236-247.

van de Walle, D., M. Ravallion, V. Mendiratta, and G. Koolwal (2015), 'Long-term gains from electrification in rural India', World Bank Economic Review lhv057.

Venkataraman, C., A.D. Sagar, G. Habib, N. Lam, and K.R. Smith (2010), 'The Indian national initiative for advanced biomass cookstoves: the benefits of clean combustion', Energy for Sustainable Development 14: 63-72.

WHO (World Health Organization) (2008), The Global Burden of Disease: 2004 Update, [Available at] http://www.who.int/healthinfo/global_burden_disease/GBD_ report_2004update_full.pdf.

Winkler, H., A.F. Simões, E.L. La Rovere, M. Alam, A. Rahman, and S. Mwakasonda (2011), 'Access and affordability of electricity in developing countries', World Development 39: 1037-1050.

Wolfram, C., O. Shelef, and P. Gertler (2012), 'How will energy demand develop in the developing world?', Journal of Economic Perspectives 26: 119-138.

Yu, F. (2011), 'Indoor air pollution and children's health: net benefits from stove and behavioral interventions in rural China', Environmental and Resource Economics 50: 495-514.

Zhang, J. and K.R. Smith (2007), 'Household air pollution from coal and biomass fuels in China: measurements, health impacts, and interventions', Environmental Health Perspectives 115: 848-855. 